\title{
Factors on the Pathway from Trauma to Suicidal Ideation in Adolescents
}

\author{
Seo Young Kwon ${ }^{1}$, Ji Ae Nam², Boo Sung Ko${ }^{2}$, Chang Wha Lee ${ }^{1}$, and Kyeong-Sook Choi ${ }^{1,2}$ \\ ${ }^{1}$ Department of Neuropsychiatry, Eulji University School of Medicine, Eulji University Hospital, Daejeon, Korea \\ ${ }^{2}$ Daedeok-gu Mental Health Center, Daejeon, Korea
}

\begin{abstract}
Objectives: Suicide is the most frequent cause of death among Korean adolescents, and adolescents who have experienced trauma have an increased risk of post-traumatic stress disorder (PTSD) symptoms, depression, and suicide attempts. However, resilience and self-esteem are protective factors. We examined the effects of resilience and self-esteem on the relationship among traumatic experiences, PTSD symptoms, depression, and suicidal ideation.

Methods: Middle-school students $(\mathrm{n}=403)$ completed questionnaires assessing traumatic experiences, PTSD symptoms, depression, suicidal ideation, resilience, and self-esteem. Path analysis was performed to investigate the mediating effects of PTSD symptoms, resilience, self-esteem, and depression on the relationship between trauma exposure and suicidal ideation.

Results: Traumatic experience was positively correlated with PTSD symptoms, depression, and suicidal ideation. PTSD symptoms and depression were positively correlated with suicidal ideation. The relationship between traumatic experiences and suicidal ideation was mediated by PTSD symptoms, which had both direct and indirect effects on suicidal ideation; the indirect effect was mediated by resilience, self-esteem, and depression.

Conclusion: Korean adolescents who had experienced trauma were more likely to develop PTSD symptoms, increasing their risk of depression and suicidal ideation. However, self-esteem and resilience may help protect against depression and suicidal ideation. Our findings could inform suicide prevention initiatives.
\end{abstract}

Key Words: Traumatic stress; Post-traumatic stress disorder; Depression; Suicidal ideation; Resilience; Self-esteem; Adolescents.

Received: July 16, 2018 / Revision: August 25, 2018 / Accepted: October 11, 2018

Address for correspondence: Kyeong-Sook Choi, Department of Neuropsychiatry, Eulji University School of Medicine, Eulji University Hospital, 95 Dunsanseo-ro, Seo-gu, Daejeon 35233, Korea

Tel: +82-42-611-3443, Fax: +82-42-611-3445, E-mail: cksinj@eulji.ac.kr

\section{INTRODUCTION}

Suicide is a major clinical and social problem worldwide and a particularly prominent issue in Korea, which has the highest suicide rate among the Organization for Economic Cooperation and Development countries [1]. Suicide is the fifth most frequent cause of death among the general population and is the leading cause of death among Korean adolescents [2]. Indeed, in Korean adolescents, the suicide rate in 2016 was 4.9 per 100000 , comprising $30.0 \%$ of the total adolescent death rate [2].

It is important to identify both the risk and protective factors for suicide in adolescents at high risk and to implement systematic interventions targeted at this group. Previous studies have shown that psychiatric disorders, including depression and anxiety, traumatic life experiences, family environ-

This is an Open Access article distributed under the terms of the Creative Commons Attribution Non-Commercial License (https://creativecommons.org/licenses/by-nc/4.0) which permits unrestricted non-commercial use, distribution, and reproduction in any medium, provided the original work is properly cited. ment, substance abuse, and academic stress are risk factors for increased suicidal ideation among adolescents [3]. In contrast, therapeutic intervention, religion, self-esteem, resilience, and family support are reportedly protective factors against adolescent suicide [4].

A previous study that surveyed the worldwide epidemiology of traumatic event exposure reported that over $70 \%$ of respondents had experienced a traumatic event during their lifetime [5]. Indeed, numerous studies have shown that approximately $25 \%$ to $61 \%$ of children and adolescents have been exposed to at least one potentially traumatic incident [6]. Posttraumatic stress disorder (PTSD), depression, and suicidal ideation were highly prevalent among adolescents exposed to traumatic events $[7,8]$. Whereas some studies have suggested that PTSD symptoms increase suicide risk among those who have experienced trauma, others have argued that the risk of suicide is higher in these individuals because of other relevant psychiatric conditions [7]. Indeed, high rates of major depression in individuals diagnosed with PTSD were 
found to compound the risk of suicide [7].

Self-esteem [9] and resilience [10] are considered positive internal resources associated with individual personality characteristics. In general, resilience helps alleviate behavioral and emotional problems and allows for healthy adaptation despite stress, adversity, or a threatening environment [11]. One study with adolescents found that resilience moderated the relationship between traumatic experiences and PTSD symptoms [12]. Additionally, resilience reduced suicide attempts in depressed adolescents who had experienced lifetime violent events [13]. Self-esteem is considered an important internal psychological resource that mitigates the effects of stress on an individual's capacity for psychological adjustment and serves as an important resource that can alleviate the effects of life stress on suicidal ideation [14]. Another study showed that self-esteem protected against suicidal ideation by mediating depressive symptoms in adolescents who had experienced traumatic events [15].

The associations among traumatic experiences, psychological maladjustment, and protective factors have been analyzed by several studies [7,12-16]. However, integrated research that explores the mechanisms by which exposure to traumatic life events leads to the development of suicidal ideation in Korean community-dwelling adolescents is relatively rare. The purpose of this study was to develop a better understanding of the mediating role of resilience, self-esteem, PTSD symptoms, and depression in the development of suicidal ideation in the context of traumatic life events in adolescents. The present study explored the direct and indirect associations between life traumatic events, PTSD symptoms, depression, resilience, self-esteem, and suicidal ideation among Korean community adolescents.

\section{METHODS}

\section{Participants and procedure}

A total of 488 middle school students residing in an urban Korean area participated in the present study. Eighty-five students were excluded from the final analyses due to missing data or low response reliability (e.g., providing the same response to all questions). Finally, 403 students were included in this study. The demographic characteristics of the study participants are presented in Table 1. The participants completed the Korean versions of the questionnaires, including the Life Events Checklist (LEC), Child Reports of Post-traumatic Symptoms (CROPS), Center for Epidemiologic Studies Depression Scale (CES-D), Connor-Davidson Resilience Scale-2 (CD-RISC2), Rosenberg Self-Esteem Scale (RSES), and Reynolds Suicidal Ideation Questionnaire (RSIQ). All data were assigned numeric identifiers to ensure participant confidenti-
Table 1. Demographic characteristics of study subjects $(n=403)$

\begin{tabular}{|c|c|}
\hline Characteristics & $\mathrm{N}(\%)$ \\
\hline \multicolumn{2}{|l|}{ Sex } \\
\hline Male & $205(50.9)$ \\
\hline Female & $198(49.1)$ \\
\hline \multicolumn{2}{|l|}{ Age (years) } \\
\hline 12 & $27(6.7)$ \\
\hline 13 & $19(4.7)$ \\
\hline 14 & $357(88.6)$ \\
\hline \multicolumn{2}{|l|}{ Religion } \\
\hline Protestantism & $111(27.5)$ \\
\hline Buddhism & $53(13.2)$ \\
\hline Catholicism & $27(6.7)$ \\
\hline Others & $2(0.5)$ \\
\hline No religion & $210(52.1)$ \\
\hline \multicolumn{2}{|l|}{ School grade } \\
\hline Good & $123(30.5)$ \\
\hline Fair & $164(40.7)$ \\
\hline Poor & $116(28.8)$ \\
\hline \multicolumn{2}{|l|}{ Socioeconomic status } \\
\hline High & $121(30.0)$ \\
\hline Middle & $239(59.2)$ \\
\hline Low & $43(10.8)$ \\
\hline \multicolumn{2}{|l|}{ Father's academic background } \\
\hline$\geq$ University & $197(60.1)$ \\
\hline High school & $124(37.8)$ \\
\hline$\leq$ Middle school & $7(2.1)$ \\
\hline \multicolumn{2}{|l|}{ Mother's academic background } \\
\hline$\geq$ University & $187(56.2)$ \\
\hline High school & $138(41.4)$ \\
\hline$\leq$ Middle school & $8(2.4)$ \\
\hline Subjects experienced traumatic events & $195(48.4)$ \\
\hline
\end{tabular}

ality and stored accordingly. The purpose of the study, and its contents and procedure, were explained to the subjects. In addition, information regarding the study was sent to the students' homes. Written informed consent was obtained from students and their parents or guardians. The total completion time for the measures ranged from 40 to $50 \mathrm{~min}$. This study was approved by the Institutional Review Board of Eulji University Hospital (Eulji Medical Center 2014-07-009-001).

\section{Assessments}

Demographic information such as sex, age, religion, school grade (the level of school performance), socioeconomic status (self-perceived family economic status), and parents' academic background was obtained through self-report questionnaires.

Traumatic events were identified using the validated Korean version of the LEC for Diagnostic and Statistical Manual 
of Mental Disorders-5 (LEC-5) [17]. The LEC addresses 17 domains of potentially traumatic events, such as disasters, accidents, physical and sexual assault, and combat-related events; these are presented in a multiple choice format that allows respondents to specify different levels of exposure to these events ("experienced," "witnessed," "learned of," "not sure," and "does not apply"). The number of traumatic events experienced was summed and included in the final analyses. The Korean version of the LEC has been standardized and showed good internal consistency (Cronbach's alpha $=0.67$ ) and convergent validity [17].

PTSD symptoms were measured using the validated Korean version of the CROPS [18]. The CROPS is a self-report measure for children and adolescents that assesses a broad range of post-traumatic symptoms. It includes 26 items that are rated on a three-point scale ranging from 0 to 2 , with no items reversely scored. The total score indicates the severity of the post-traumatic stress reactions (range of possible scores: $0-52$ ). The Korean version of the CROPS has shown excellent internal consistency (Cronbach's alpha $=0.91$ ) and high test-retest reliability (Pearson $r>0.9$ ) [18].

Depression was measured using the validated Korean version of the CES-D [19]. The CES-D is a self-report questionnaire designed to measure depressive symptoms in the general population. It consists of 20 items scored on a scale ranging from 0 to 3. Higher total scores reflect higher levels of depressive symptoms. The Korean version of the CES-D has been standardized and showed good validity and internal consistency in samples of depressed individuals (Cronbach's alpha= $0.90)$ [19] and community-dwelling adolescents (Cronbach's alpha $=0.88$ ) [20].

Suicidal ideation was measured using the Korean version of the RSIQ [21]. The 30 RSIQ items examine thoughts about, and views of, suicidal ideation. Each item is scored on a sevenpoint Likert scale ranging from 0 to 6 . The means of all items are summed to obtain a total score (range: $0-180$ ); higher total scores indicate higher levels of suicidal ideation. The Korean version of the RSIQ has demonstrated excellent internal consistency (Cronbach's alpha=0.97) [21].

Individual resilience was measured using the validated Korean version of the CD-RISC2 [10]. This two-item scale is rated on a five-point Likert scale ranging from 0 ("not true at all") to 4 ("true nearly all of the time"). Total scores range from 0 to 8 , with higher scores indicating greater resilience. This measure has demonstrated good internal consistency (Cronbach's alpha $=0.75$ ) and convergent validity [10].

Self-esteem was measured using the Korean version of the RSES (K-RSES) [9]. The RSES consists of 10 items that measure positive and negative aspects of self-esteem. All items are rated on a four-point scale ranging from 1 ("strongly disagree") to 4 ("strongly agree"). Total scores range from 10 to 40 , with higher scores indicating higher levels of self-esteem. The KRSES has shown excellent internal consistency (Cronbach's alpha $=0.90)$ and high reliability [9].

\section{Statistical analyses}

Descriptive statistics were used to summarize the demographic and clinical characteristics of participants. Correlational analyses of six variables (traumatic events, post-traumatic symptoms, depressive symptoms, suicidal ideation, individual resilience, and self-esteem) were performed. Ttest or one-way analysis of variance (ANOVA) were used to assess the differences in suicidal ideation according to demographic variables. Significant differences identified in the ANOVA were further explored with the Scheffe post-hoc test. Multiple regression analysis was performed to evaluate the relationships between psychological variables and suicidal ideation. In this analysis, non-continuous variables were included by dummy variable treatment. Finally, the identified factors associated with suicidal ideation were included in a path analysis model. Experience of a traumatic event was the predictor variable, suicidal ideation was the outcome variable, and PTSD symptoms, resilience, self-esteem, and depression were considered mediators. Sex and socioeconomic status, which may affect suicidal ideation, were set as control variables. A number of fit statistics were chosen to determine the goodness of fit of the model: 1) the chi-squared statistic, 2) goodness of fit index (GFI, $\geq 0.95), 3$ ) root mean square error of approximation (RMSEA, $\leq 0.06$ ), 4) Tucker-Lewis index (TLI, $\geq 0.95$ ), 5) normed fit index (NFI, $\geq 0.95$ ), and 6) comparative fit index (CFI, $\geq 0.95$ ) [22]. Path coefficients are presented as standardized regression weights ( $\beta$ ). All statistical analyses were performed using SPSS (ver. 14.0; SPSS Inc., Chicago, IL, USA) and AMOS (ver. 7.0; SPSS Inc., Chicago, IL, USA). The statistical significance was set at the $5 \%$ level.

\section{RESULTS}

\section{Demographic characteristics of the sample}

Study participants were 12 to 14 years of age; $50.9 \%(n=205)$ were male. Based on the self-perceived school performance, $30.6 \%$ of subjects $(n=123)$ had a good school grade, $40.5 \%$ $(\mathrm{n}=163)$ had a fair school grade, and $28.9 \%(\mathrm{n}=116)$ had a poor school grade. Based on the self-perceived family economic status, $30.0 \%(\mathrm{n}=121)$ were classified as having high socioeconomic status, $59.2 \%(\mathrm{n}=239)$ as having middle socioeconomic status, and $10.8 \%(\mathrm{n}=43)$ as having low socioeconomic status. Additional details regarding the characteristics of the study participants are presented in Table 1. 


\section{Experience of traumatic life events}

A considerable proportion of participants ( $n=195,48.4 \%)$ had experienced at least one potential traumatic event in life. The most frequent traumatic events were natural disaster (51.8\%), motor vehicle accident (33.3\%), and other very stressful event (20.5\%). Of the 195 subjects who had experienced a traumatic life event, 119 (61.0\%) had experienced one traumatic event, 43 (22.1\%) had experienced two traumatic events, and 33 (16.9\%) had experienced more than three traumatic events. Additional details on the type and frequency of traumatic life events are presented in Table 2.

\section{Preliminary correlation analyses}

The correlations among the six primary variables were examined. Traumatic events were positively associated with PTSD symptoms, depression, and suicidal ideation. PTSD symptoms were positively associated with depression and suicidal ideation, and inversely associated with resilience and self-esteem. Depression was positively associated with suicidal ideation, and negatively associated with resilience and selfesteem. Suicidal ideation was inversely associated with resilience and self-esteem. Finally, self-esteem was significantly associated with individual resilience (all $\mathrm{p}<0.01$ ).

\section{Results of the analysis predicting suicidal ideation}

Table 3 shows the statistically significant differences in suicidal ideation as a function of sex and socioeconomic status.

Table 2. Type and frequency of life traumatic events ( $n=195$ )

\begin{tabular}{lc}
\hline \multicolumn{1}{c}{ Type of trauma } & Frequency $(\mathrm{n}, \%)$ \\
\hline Natural disaster & $101(51.8)$ \\
Motor vehicle accident & $65(33.3)$ \\
Other very stressful event & $40(20.5)$ \\
Physical assault & $31(15.9)$ \\
Fire/explosion & $18(9.2)$ \\
Other serious accident & $18(9.2)$ \\
Other unwanted sexual experience & $15(7.7)$ \\
Life-threatening injury/illness & $9(4.6)$ \\
Caused serious injury/death of another & $4(2.1)$ \\
Assault with a weapon & $3(1.5)$ \\
Sexual assault & $3(1.5)$ \\
Witness violent death & $3(1.5)$ \\
Sudden, unexpected death & $3(1.5)$ \\
of someone close & \\
Number of endorsed traumatic events & \\
1 & $119(61.0)^{*}$ \\
2 & $43(22.1)^{*}$ \\
3 & $25(12.8)^{*}$ \\
4 & $7(3.6)^{*}$ \\
5
\end{tabular}

${ }^{*}$ number (\%) of subjects in each category
Suicidal ideation was significantly higher in female than in male subjects $(\mathrm{t}=-4.144, \mathrm{p}<0.001)$ and in subjects with low socioeconomic status than in those with middle/high socioeconomic status $(\mathrm{F}=6.240, \mathrm{p}<0.01)$. However, there were no statistically significant differences in suicidal ideation according to age, school grade, or parental academic background.

Table 4 shows the results of the multiple regression analysis to explore the factors that predicted suicidal ideation. PTSD symptoms and depression positively predicted suicidal ideation. However, self-esteem was a negative predictor of suicidal ideation.

\section{Path analysis for the mediation analyses}

The results of the path analysis of the association between traumatic experiences and suicidal ideation are shown in Table 5 and Fig. 1. To adjust for demographic characteristics that may affect suicidal ideation, sex and socioeconomic status were included as control variables in the path analysis. This model was a good fit for the data $\left(\chi^{2}=9.492, \mathrm{df}=4, \mathrm{GFI}=\right.$ $0.988, \mathrm{NFI}=0.985, \mathrm{TLI}=0.975$, RMSEA $=0.056, \mathrm{CFI}=0.990$ ). As shown in Fig. 1, all paths in the model were statistically significant. Traumatic experience was significantly associated with PTSD symptoms $(\beta=0.218, \mathrm{p}<0.001)$. PTSD symptoms negatively predicted resilience $(\beta=-0.314, p<0.001)$ and selfesteem $(\beta=-0.462, \mathrm{p}<0.001)$ and positively predicted depression $(\beta=0.431, \mathrm{p}<0.001)$ and suicidal ideation $(\beta=0.201, \mathrm{p}<0.001)$. Self-esteem negatively predicted depression $(\beta=-0.452, \mathrm{p}<0.001)$ and suicidal ideation $(\beta=-0.168, \mathrm{p}<0.01)$. Furthermore, resilience negatively predicted depression $(\beta=-0.083, \mathrm{p}<0.01)$ and suicidal ideation $(\beta=-0.081, \mathrm{p}<0.05)$. Depression was significantly associated with suicidal ideation $(\beta=0.330, p<0.001)$. PTSD symptoms mediated the relationship between traumatic experiences and suicidal ideation. Self-esteem, resilience, and depression also partially mediated the relationship between traumatic experiences and suicidal ideation. The squared multiple correlation was 0.353 for suicidal ideation, indicating that this model accounted for $35.3 \%$ of the variance in suicidal ideation.

\section{DISCUSSION}

This study yielded two key findings. First, traumatic experience in Korean adolescents affected PTSD symptoms and PTSD symptoms directly affected suicidal ideation or indirectly affected suicidal ideation caused by increased depression. Second, the mediating effects of resilience and self-esteem on the path from traumatic experience to suicidal ideation were confirmed.

The first major finding of the present investigation was that a considerable proportion of subjects (48.4\%) had experienced 
Table 3. Suicidal ideation according to demographic variables $(n=403)$

\begin{tabular}{|c|c|c|c|}
\hline \multirow{2}{*}{ Variables } & \multicolumn{3}{|c|}{ Suicidal ideation } \\
\hline & Mean \pm SD & $t / F$ & $\mathrm{p}$ \\
\hline \multicolumn{4}{|l|}{ Sex } \\
\hline Male & $5.32 \pm 11.45$ & $-4.144^{\ddagger}$ & $<0.001$ \\
\hline Female & $13.80 \pm 24.82$ & & \\
\hline \multicolumn{4}{|l|}{ Age (years) } \\
\hline 13 & $11.43 \pm 27.87$ & 0.135 & 0.873 \\
\hline 14 & $9.63 \pm 17.09$ & & \\
\hline 15 & $9.38 \pm 19.20$ & & \\
\hline \multicolumn{4}{|l|}{ Religion } \\
\hline Religion & $10.21 \pm 20.99$ & 0.602 & 0.547 \\
\hline No religion & $8.95 \pm 18.40$ & & \\
\hline \multicolumn{4}{|l|}{ School grade } \\
\hline Good & $10.39 \pm 18.20$ & 0.399 & 0.671 \\
\hline Fair & $8.39 \pm 19.30$ & & \\
\hline Poor & $10.19 \pm 21.74$ & & \\
\hline \multicolumn{4}{|l|}{ Socioeconomic status } \\
\hline High & $12.07 \pm 31.29^{a}$ & $6.240^{\dagger}$ & 0.002 \\
\hline Middle & $9.44 \pm 19.05^{a}$ & & \\
\hline Low & $17.07 \pm 24.43^{\mathrm{b}}$ & & \\
\hline \multicolumn{4}{|l|}{ Father's academic background } \\
\hline 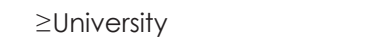 & $9.08 \pm 17.69$ & 1.636 & 0.197 \\
\hline High school & $9.96 \pm 20.58$ & & \\
\hline$\leq$ Middle school & $22.14 \pm 26.42$ & & \\
\hline \multicolumn{4}{|c|}{ Mather's academic background } \\
\hline$\geq$ University & $8.89 \pm 17.22$ & 2.648 & 0.072 \\
\hline High school & $9.42 \pm 18.20$ & & \\
\hline$\leq$ Middle school & $25.29 \pm 43.77$ & & \\
\hline \multicolumn{4}{|l|}{ Number of traumatic events } \\
\hline 0 & $8.39 \pm 23.11^{a}$ & & \\
\hline 1 & $12.28 \pm 24.32^{a}$ & $3.213^{*}$ & 0.041 \\
\hline$\geq 2$ & $16.37 \pm 27.31^{\mathrm{b}}$ & & \\
\hline
\end{tabular}

Post-hoc: $a<b .{ }^{*} p<0.05,{ }^{\dagger} p<0.01,{ }^{\ddagger} p<0.001$. SD: standard deviation

a traumatic life event. Compared to other studies with population samples having examined this issue, this rate is similar to the results reported by Copeland et al. [6]. The most frequent traumatic event was "natural disaster" (25.1\%). The rate of natural disaster exposure in this study is similar to the results reported by a previous study [23] that assessed the lifetime prevalence of traumatic exposure and the epidemiology of PTSD. Multiple traumata were experienced by $39.0 \%$ of those with trauma experience, and multiple traumatic events were more likely to result in suicidal ideation.

The outcomes of this study are partly consistent with those of previous studies with adolescents that addressed the pathway from traumatic experiences to suicidal ideation. Choi et al. [24] reported that happiness mediated the negative relationship between the experience of violence and poor peer support. However, we investigated a wide range of lifetime traumatic experience. Additionally, the positive psychological factors considered in our study included self-esteem and resilience rather than happiness. Previous studies with Taiwanese adolescents who experienced typhoon-induced mudslides showed that disaster exposure, female sex, and family support had direct and indirect effects on suicide risk, which were mediated by PTSD and major depressive disorder [25]. A longitudinal study with adolescents who experienced Hurricane Andrew reported that being female, low socioeconomic status, depression, high stress scores, and low family support had significant direct/indirect effects on suicidal ideation [26]. Our study investigated the associations among lifetime traumatic experiences, PTSD symptoms, resilience, self-esteem, depression, and suicidal ideation. Traumatic experi- 
Table 4. Multiple regression analysis for factors associated with suicidal ideation $(n=403)$

\begin{tabular}{|c|c|c|c|c|c|c|c|c|c|}
\hline \multirow{2}{*}{ Variables } & \multirow{2}{*}{ Mean $\pm S D$} & \multicolumn{4}{|c|}{ Simple linear regression } & \multicolumn{4}{|c|}{ Adjusted multiple regression analysis } \\
\hline & & B & $\beta$ & $t$ & $\mathrm{p}$ & B & $\beta$ & $t$ & $\mathrm{p}$ \\
\hline Sex (female) & & & & & & 1.11 & 0.02 & 0.55 & 0.59 \\
\hline \multicolumn{10}{|c|}{ SES dummy variables } \\
\hline Low vs. middle & & & & & & -5.81 & -0.11 & -2.63 & 0.009 \\
\hline Low vs. high & & & & & & -3.42 & -0.06 & -0.97 & 0.34 \\
\hline LEC & $0.78 \pm 1.01$ & 3.13 & 0.13 & 2.61 & 0.009 & 0.60 & 0.03 & 0.59 & 0.55 \\
\hline CES-D & $11.47 \pm 8.88$ & 1.55 & 0.56 & 13.62 & $<0.001$ & 0.91 & 0.33 & 4.64 & $<0.001$ \\
\hline CROPS & $7.41 \pm 8.23$ & 1.51 & 0.51 & 11.79 & $<0.001$ & 0.57 & 0.19 & 3.26 & 0.001 \\
\hline RSES & $31.96 \pm 5.67$ & -2.10 & -0.49 & -11.16 & $<0.001$ & -0.78 & -0.18 & -2.87 & 0.004 \\
\hline \multirow[t]{2}{*}{ CD-RISC2 } & $5.64 \pm 1.79$ & -2.86 & -0.21 & -4.30 & $<0.001$ & 1.17 & 0.08 & 1.81 & 0.071 \\
\hline & & & & & & \multicolumn{4}{|c|}{$R^{2}=0.365$, adjusted $R^{2}=0.352, F=28.273, p<0.00$} \\
\hline
\end{tabular}

CD-RISC2: Connor-Davidson Resilience Scale-2, CES-D: Center for Epidemiologic Studies Depression Scale, CROPS: Child Reports of Post-traumatic Symptoms, LEC: Life Events Checklist, RSES: Rosenberg Self-Esteem Scale, SD: standard deviation, SES: socioeconomic status

Table 5. Results of path analysis $(n=403)$

\begin{tabular}{|c|c|c|c|c|}
\hline \multirow{2}{*}{ Dependent variable } & \multirow{2}{*}{ Independent variable } & \multicolumn{2}{|c|}{ Regression coefficients } & \multirow{2}{*}{$R^{2}$} \\
\hline & & Standardized & $\mathrm{p}$ & \\
\hline \multirow[t]{4}{*}{ Suicidal ideation } & PTSD symptoms & 0.201 & $<0.001$ & 0.353 \\
\hline & Depression & 0.330 & $<0.001$ & \\
\hline & Resilience & -0.081 & 0.047 & \\
\hline & Self-esteem & -0.168 & 0.007 & \\
\hline \multirow[t]{3}{*}{ Depression } & PTSD symptoms & 0.431 & $<0.001$ & 0.678 \\
\hline & Resilience & -0.083 & 0.010 & \\
\hline & Self-esteem & -0.452 & $<0.001$ & \\
\hline \multirow[t]{2}{*}{ Self-esteem } & PTSD symptoms & -0.462 & $<0.001$ & 0.432 \\
\hline & Resilience & 0.345 & $<0.001$ & \\
\hline Resilience & PTSD symptoms & -0.314 & $<0.001$ & 0.098 \\
\hline PTSD symptoms & Traumatic events & 0.218 & $<0.001$ & 0.057 \\
\hline
\end{tabular}

PTSD: post-traumatic stress disorder

ences affected PTSD symptoms, and the mediating effects of depression on the association between PTSD symptoms and suicidal ideation were, in turn, mediated by resilience and self-esteem. We found statistically significant differences in suicidal ideation as a function of sex and socioeconomic status.

Several studies have examined whether individual psychological characteristics and coping resources increase or decrease the suicidal ideation attributable to traumatic experiences. It has been reported that self-esteem is a protective factor mediating the relationship between stress and suicidal ideation [14] and that resilience is negatively associated with depression and suicidal ideation [13]. These results were also confirmed in this study. Studies have shown that resilience buffers the impact of traumatic events with regard to the development of PTSD symptoms [12]. Unlike previous studies, we did not find any mediating effects of resilience on the relationship between traumatic stress and PTSD symptoms. This may be due to the unique characteristics of adolescents, their relationships with their environments, and their developmental stage. Resilience can be conceptualized as a dynamic process that changes over time depending on the interactions between genetic factors and the environment [27]. Future followup studies should explore changes in clinical symptoms and positive psychological characteristics and confirm their effects on the pathway from traumatic experiences to suicidal ideation. In terms of traumatic experience, our study investigated lifetime traumatic events in local middle school students. However, previous studies $[25,26,28]$ examined survivors of a single traumatic event, such as war or a specific disaster.

Religion and family support have been shown to be protective factors against suicidal ideation [4]. In the present study, no statistically significant difference was observed in suicidal ideation according to religious type $(\mathrm{F}=0.872, \mathrm{p}=0.48)$ or religious presence $(\mathrm{t}=0.602, \mathrm{p}=0.547)$. In the previous study, it has been reported that being a Christian has a protective effect 


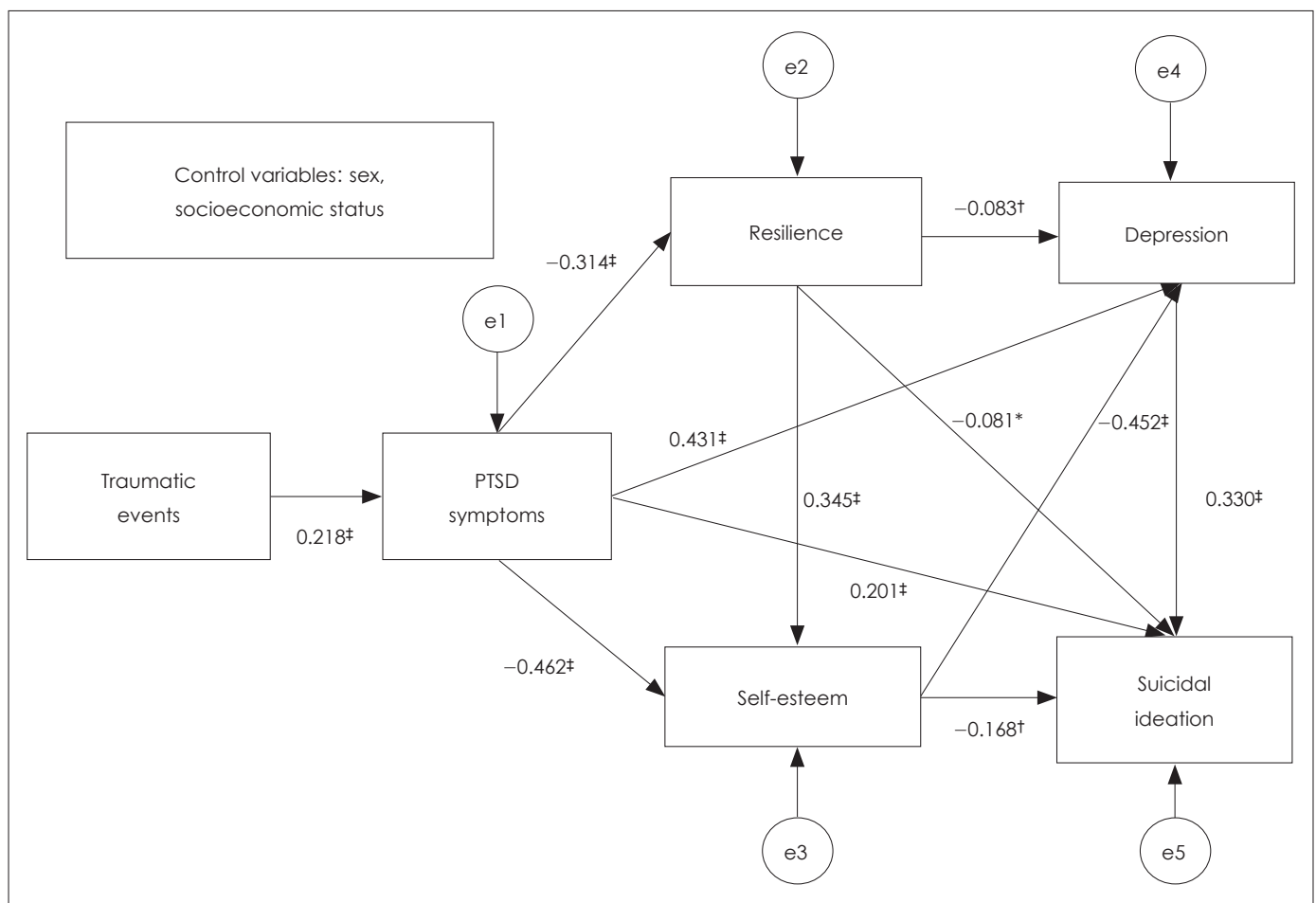

Fig. 1. Path diagrams showing relationships among traumatic events, PTSD symptoms, resilience, self-esteem, depression, and suicidal ideation. ${ }^{*} p<0.05,{ }^{\dagger} p<0.01,{ }^{\ddagger} p<0.001$. PTSD: post-traumatic stress disorder.

on suicidal ideation in trauma exposure groups [29]. However, there was no significant difference in suicidal ideation when the sample population was divided into Christians and nonChristians in this study $(\mathrm{t}=-1.616, \mathrm{p}=0.107)$. We did not measure family support but did investigate self-reported satisfaction with relationships with parents and siblings. However, these data were not included in the final analysis due to excessive amount of missing values. Anxiety and social support mediated the relationship between childhood trauma and suicidal ideation [30]. According to a study with veterans, the protective effect of exercise on suicide risk was mediated by depression, PTSD symptoms, and sleep disturbances [31]. Future studies should further analyze the protective factors against suicidal ideation in adolescents who have undergone traumatic experiences.

This study had several limitations. First, the cross-sectional design limited the ability to infer a causal relationship between the variables that were investigated. Thus, the results should be interpreted with caution, and future research using longitudinal and experimental designs is needed to clarify the direction of any causal relationships between the observed variables. Second, the generalizability of the results is limited; subjects were only recruited from middle schools in certain areas, and random probability sampling was not used, decreasing the generalizability of the results to the clinical population. Further research with the actual clinical popula- tion is needed, including subjects with known PTSD, depression, suicide attempt history, and/or suicidal ideation. Third, due to the self-report nature of this study, the possibility of various types of error exists, including exaggeration or underreporting. In addition, the subjects' current depressive state or suicidal ideation may have affected reports of past traumatic experiences, self-esteem, and/or resilience. Although all included scales have been validated, future studies utilizing standardized interviews and more extensive cohorts (involving parents and teachers), or using observational methods, would provide more accurate and detailed information regarding the complex mechanisms underlying the relationship between traumatic stress and the development of PTSD symptoms, depression, and suicidal ideation. Finally, previous studies have reported that substance use disorders are highly prevalent in individuals with PTSD and are also associated with increases in suicidal behavior [3,7], but this study did not measure substance use. Future research is necessary to explore a greater number of mediators, including substance abuse, to elucidate the specific mechanisms underlying the relationship between trauma exposure and suicidal ideation.

\section{CONCLUSION}

In summary, the interaction among traumatic life events, depression, PTSD symptoms, and positive psychological 
factors such as resilience and self-esteem may contribute to the development of suicidal ideation in adolescents. The results of this study indicate the importance of early intervention and prevention of suicidal ideation among middle school students and the importance of promoting resilience and self-esteem in suicidal individuals. Furthermore, the risk and protective factors for youth suicide identified in the present study could be used to inform school curricula, interventions, and suicide prevention policies.

\section{Acknowledgments}

This research was supported by EMBRI Grants 2014EMBRI DI0003 from the Eulji University.

\section{Conflicts of Interest}

The authors have no financial conflicts of interest.

\section{REFERENCES}

1) OECD. OECD Health statistics 2016. Paris: OECD;2016.

2) Korea Statistics. Annual report on the cause of death statistics. Daejeon: Statistics Korea;2016.

3) Kim SW, Kim SY, Yang SJ, Kim JM, Shin IS, Jeong S, et al. Psychosocial correlates of suicidal ideation in middle-school students. J Korean Neuropsychiatr Assoc 2010;49:604-610.

4) George A, Moolman R. Resilience and suicide ideation: coping mediator-moderator effects among adolescent learners. Journal of Psychology in Africa 2017;27:494-502.

5) Benjet C, Bromet E, Karam EG, Kessler RC, McLaughlin KA, Ruscio AM, et al. The epidemiology of traumatic event exposure worldwide: results from the World Mental Health Survey Consortium. Psychol Med 2016;46:327-343.

6) Copeland WE, Keeler G, Angold A, Costello EJ. Traumatic events and posttraumatic stress in childhood. Arch Gen Psychiatry 2007; 64:577-584.

7) Wilcox HC, Storr CL, Breslau N. Posttraumatic stress disorder and suicide attempts in a community sample of urban American young adults. Arch Gen Psychiatry 2009;66:305-311.

8) Kang NR, Chung US, Kwack YS. Impact of peer's suicide on mental health of adolescents. J Korean Acad Child Adolesc Psychiatry 2015; 26:266-272.

9) Bae HN, Choi SW, Yu JC, Lee JS, Choi KS. Reliability and validity of the Korean version of the rosenberg self-esteem scale (K-RSES) in adult. J of Kor Soc for Dep and Bip Disorders 2014;12:43-49.

10) Jeong HS, Kang I, Namgung E, Im JJ, Jeon Y, Son J, et al. Validation of the Korean version of the Connor-Davidson Resilience Scale-2 in firefighters and rescue workers. Compr Psychiatry 2015;59:123-128.

11) Block J, Kremen AM. IQ and ego-resiliency: conceptual and empirical connections and separateness. J Pers Soc Psychol 1996;70:349361.

12) Fincham DS, Altes LK, Stein DJ, Seedat S. Posttraumatic stress disorder symptoms in adolescents: risk factors versus resilience moderation. Compr Psychiatry 2009;50:193-199.

13) Nrugham L, Holen A, Sund AM. Associations between attempted suicide, violent life events, depressive symptoms, and resilience in adolescents and young adults. J Nerv Ment Dis 2010;198:131-136.
14) Folkman S. Stress: appraisal and coping. In: Gellman MD, Turner JR, editors. Encyclopedia of behavioral medicine. New York: Springer; 2013. p.1913-1915.

15) Arslan G. Psychological maltreatment, emotional and behavioral problems in adolescents: the mediating role of resilience and selfesteem. Child Abuse Negl 2016;52:200-209.

16) Ramsawh HJ, Fullerton CS, Mash HB, Ng TH, Kessler RC, Stein MB, et al. Risk for suicidal behaviors associated with PTSD, depression, and their comorbidity in the U.S. Army. J Affect Disord 2014;161:116-122.

17) Bae H, Kim D, Koh H, Kim Y, Park JS. Psychometric properties of the life events checklist-Korean version. Psychiatry Investig 2008; 5:163-167.

18) Lee KM, Jeong SH, Lee WK, Chung US. Reliability and validity of the Korean version of the child report of post-traumatic symptoms (CROPS) and the parent report of post-traumatic symptoms (PROPS). J Korean Acad Child Adolesc Psychiatry 2011;22:169-181.

19) Cho MJ, Kim KH. Diagnostic validity of the CES-D (Korean version) in the assessment of DSM-III-R major depression. J Korean Neuropsychiatr Assoc 1993;32:381-399.

20) Heo EH, Choi KS, Yu JC, Nam JA. Validation of the center for epidemiological studies depression scale among Korean adolescents. Psychiatry Investig 2018;15:124-132.

21) Shin MS. An empirical study of the mechanism of suicide: validation of the scale for escape from the self. Seoul: Yonsei Univ.;1992.

22) Hu L, Bentler PM. Cutoff criteria for fit indexes in covariance structure analysis: conventional criteria versus new alternatives. Struct Equ Model 1999;6:1-55.

23) Eun HJ, Lee SM, Kim TH. The epidemiological study of posttraumatic stress disorder in an urban area. J Korean Neuropsychiatr Assoc 2001;40:581-591.

24) Choi JH, Yu M, Kim KE. Suicidal ideation in adolescents: a structural equation modeling approach. Nurs Health Sci 2015;17:119-125.

25) Tang TC, Yen CF, Cheng CP, Yang P, Chen CS, Yang RC, et al. Suicide risk and its correlate in adolescents who experienced typhooninduced mudslides: a structural equation model. Depress Anxiety 2010;27:1143-1148.

26) Warheit GJ, Zimmerman RS, Khoury EL, Vega WA, Gil AG. Disaster related stresses, depressive signs and symptoms, and suicidal ideation among a multi-racial/ethnic sample of adolescents: a longitudinal analysis. J Child Psychol Psychiatry 1996;37:435-444.

27) Kim-Cohen J, Gold AL. Measured gene-environment interactions and mechanisms promoting resilient development. Curr Dir Psychol Sci 2009;18:138-142.

28) Wisco BE, Marx BP, Wolf EJ, Miller MW, Southwick SM, Pietrzak RH. Posttraumatic stress disorder in the US veteran population: results from the National Health and Resilience in Veterans Study. J Clin Psychiatry 2014;75:1338-1346.

29) Stratta P, Capanna C, Riccardi I, Carmassi C, Piccinni A, Dell'Osso L, et al. Suicidal intention and negative spiritual coping one year after the earthquake of L'Aquila (Italy). J Affect Disord 2012;136:12271231.

30) Bahk YC, Jang SK, Choi KH, Lee SH. The relationship between childhood trauma and suicidal ideation: role of maltreatment and potential mediators. Psychiatry Investig 2017;14:37-43.

31) Davidson CL, Babson KA, Bonn-Miller MO, Souter T, Vannoy S. The impact of exercise on suicide risk: examining pathways through depression, PTSD, and sleep in an inpatient sample of veterans. Suicide Life Threat Behav 2013;43:279-289. 